\title{
Socioeconomic inequality in clusters of health-related behaviours in Europe: latent class analysis of a cross-sectional European
} survey

\author{
Shiho Kino*, Eduardo Bernabé and Wael Sabbah
}

\begin{abstract}
Background: Modifiable health-related behaviours tend to cluster among most vulnerable sectors of the population, particularly those at the bottom of the social hierarchy. This study aimed to identify the clusters of health-related behaviours in 27 European countries and to examine the socioeconomic inequalities in these clusters.

Methods: Data were from Eurobarometer 72.3-2009, a cross-sectional survey of 27 European countries. The analyses were conducted in 2016. The main sections of the survey included questions pertaining to sociodemographic factors, health-related behaviours, and use of services. In this study, those aged 18 years and older were included. We selected five health-related behaviours, namely smoking, excessive alcohol consumption, frequent fresh fruit consumption, physical activity and dental check-ups. Socioeconomic position was indicated by education, subjective social status and difficulty in paying bills. Latent class analysis was conducted to explore the clusters of these five behaviours.

Multinomial logistic regression model was used to examine the relationships between the clusters and socioeconomic positions adjusting for age, gender, marital status and urbanisation.

Results: The eligible total population was 23,842. Latent class analysis identified three clusters; healthy, moderate and risky clusters in this European population. Individuals with the lowest socioeconomic position were more likely to have risky and moderate clusters than healthy cluster compared to those with the highest socioeconomic position.

Conclusions: There were clear socioeconomic gradients in clusters of health-related behaviours. The findings highlight the importance of adopting interventions that address multiple health risk behaviours and policies that tackle the social determinants of health-related behaviours.
\end{abstract}

Keywords: Socioeconomic factors, Health behavior, Cluster analysis, Europe

\section{Background}

Modifiable health-related behaviours such as smoking, excessive alcohol consumption, poor diet, usually measured by fruit and vegetable consumption, and lack of physical activity have a major impact on a wide array of chronic conditions such as cancers, cardiovascular disease and diabetes, and on related mortality [1-3]. Interestingly, this set of risk behaviours is also correlated with oral health [4-7], which is related to the non-symptomatic use

\footnotetext{
* Correspondence: shiho.kino@kcl.ac.uk
Division of Population and Patient Health, King's College London Dental
Institute at Guy's, King's College and St Thomas' Hospitals, Bessemer Road,

* Correspondence: shiho.kino@kcl.ac.uk

* Correspondence: shiho.kino@kcl.ac.uk
Division of Population and Patient Health, King's College London Dental
Institute at Guy's, King's College and St Thomas' Hospitals, Bessemer Road, Denmark Hill, London SE5 9RS, UK
}

of dental services for check-ups $[8,9]$. Furthermore, these five behaviours have common socioeconomic determinants that operate through similar pathways [10]. One phenomenon about these risk behaviours is that they tend to cluster among most vulnerable sectors of the population, particularly those at the bottom of the social hierarchy $[11,12]$. Accumulation of negative life events and social disadvantage throughout the life also contributes to clustering of health risk behaviours [13]. However, there are a number of methodological challenges for clustering of health risk behaviours [14].

Given the cumulative and devastating impacts of the cluster of risk behaviours on health, there is a growing 
interest in research investigating this phenomenon to identify opportunities for effective interventions tackling multiple behaviours $[14,15]$. Most of these studies have used co-occurrence of behaviours which is a count of risk or promoting behaviours [14]. This approach assumes homogeneity in the co-occurrence of behaviours within any given population. The utilisation of more complex analytical methods, such as latent class analysis, can help understanding the complex relationships among healthrelated behaviours. Such a technique utilises probability modelling to identify actual groups of behaviours within a cluster [16]. Earlier studies used latent class analysis for health-related behaviours $[17,18]$, however, none of them has estimated clusters of the five health-related behaviours used in this study.

Identifying socioeconomic determinants of different clusters of health-related behaviours is deemed important to enable selecting an effective approach to the population at risk. Most of the studies assessing socioeconomic inequalities in health-related behaviours used objective indicators such as income and education, which reflect material and educational pathways to healthrelated behaviours $[14,18,19]$. Although the difficulty in paying bills might not accurately reflect socioeconomic hierarchy as some individuals with higher income could have difficulty in paying bills, but it undoubtedly impacts ability to engage in healthy behaviours through materialistic pathway [20, 21]. Education is also linked to social position and it enables individuals to acquire knowledge related to enhancing health-related behaviours [22]. Using these common indicators that reflect material and educational pathways also allows comparison with other studies and between countries. On the other hand, these objective indicators of socioeconomic position do not completely capture the psychosocial pathway to inequality in behaviours which plays an important role in shaping health risk behaviours [23, 24]. For instance, the perception of relative deprivation is linked to stresses, insecurity, depression and social isolation which are all related to unhealthy behaviours [19, 24-27]. Using an indicator of subjective social status which reflects individuals' perception of their social standing in their own country can capture the psychosocial pathway to inequality in health-related behaviours.

Occupation is widely used as a socioeconomic indicator, however the recent increase in low-level service jobs and decrease in manual jobs generate misleading classification of social hierarchy [28]. Furthermore, occupation classification does not capture unemployed, retired individuals, students and volunteer workers $[28,29]$. In this study we used materialistic, educational and subjective indicators of socioeconomic position to test whether inequality exists in clusters of behaviours produced by latent class analysis in 27 European countries.
This study aims to identify different clusters of healthrelated behaviours using nationally representative samples in 27 European countries, and to examine the relationships between these clusters and objective and subjective indicators of socioeconomic position.

\section{Methods}

\section{Data source and study sample}

This study is a secondary analysis of cross-sectional survey in Europe, Eurobarometer 72.3, 2009. The survey included nationally representative samples from 27 European Union countries and three candidate countries [30]. A 2-stage, random (probability) sampling design was used for sample selection [30]. The data was collected by face-to-face interview in people's home from October 2 to 19, 2009 by the TNS Opinion and Social through its network of national institutes in the respective national language. No more than one interview was conducted in each household [30].

The survey included data on 30,292 participants aged 15 years or older. The regular sample size was 1000 participants from each country with the exceptions of the United Kingdom (1000 for Great Britain and 300 for Northern Ireland), Germany (500 for the Eastern and 1000 for the Western) and Luxembourg, Cyprus Republic, Turkish Cypriot Community and Malta with 500 for each.

This study included participants who answered all questions pertaining to health-related behaviours and demographic/socioeconomic indicators. Given that smoking and drinking are illegal for those under 18 years in most of the European countries the analysis was limited to those aged 18 and over.

The survey included 26,013 participants aged 18 years or older in 27 European countries. After excluding those with missing values, 23,842 individuals aged 18 years or older in 27 European countries were included in this study (the valid percentage: $91.7 \%$ ).

\section{Variables \\ Outcomes}

The survey included questions about health-related behaviours in some domains, namely, check-up and medical screening, oral health, alcohol habits, smoking habits, and sport and physical activity. We selected five health-related behaviours, namely, smoking, excessive alcohol consumption, frequent fresh fruit consumption, physical activity which are highly correlated and linked to several noncommunicable diseases, and oral diseases. Dental checkups are also an important health-related behaviour that is linked to the aforementioned behaviours, highly related to socioeconomic indicators through the similar pathways as the other behaviours, and is not usually covered by the universal health coverage in Europe. These behaviours were dichotomised into binary options. Smoking was indicated by current smokers (versus former/never-smoker), which 
was based on self-reported with a single item. Excessive alcohol consumption was defined as having five or more drinks on one occasion at least once a week in the last 12 months. This is categorised based on the definition of risky single-occasion drinking as approximately 60-70 g ethanol for men and 40-60 g for women [31], which is equitable five standard drinks [31, 32]. Frequent fresh fruit consumption, as an indicator of healthy diet, included those who reported they often consume fruits versus those reporting "from time to time", "rarely" or "never" for nonfrequent fresh fruit consumption. A variable for physical activities was created by combining the two original questions, and was indicated by engaging in exercise, playing sports, or outdoor physical activity (e.g. cycling, walking from a place to another, dancing and gardening) at least four times a week, versus less than four times a week. European guideline indicated that physical activity at least five times a week is recommended for European adults [33]. As the dataset did not allow using this definition, in this study at least four times a week was used for physical activity as a cut-off point. Attendance for dental check-ups was indicated by use in the past 12 months either on own initiative, doctor's initiative or in a screening programme.

\section{Explanatory factors}

The survey included four indicators of socioeconomic position, namely education, subjective social status, difficulty in paying bills and occupation. Given the limitations of occupational category, particularly when used in cross-country comparison, we opted to use the first three indicators which capture three different domains of socioeconomic position. Education was measured by the age when participants stopped full-time education, and was categorised into three groups: 20 years and older, 16-19 years old and 15 years or less. In most European countries, the minimum age for the compulsory education is 15 years or older, and the secondary school education is usually completed before 20 years of age [34]. Therefore, individuals in the lowest educational category were regarded as those who did not complete compulsory education, and those in the highest category were regarded as people entered a university level education. Participants still studying were included in the category corresponding to their age. Education is an important socioeconomic indicator as it is comparable across countries [35]. Subjective social status is appropriate for the comparison across countries as it reflects one's perception of own status in the respective community/country. In the survey, participants were asked to place themselves on a ladder indicating their perception of own positions in their respective society on a scale of $1-10$, hence reflecting perception of social standing. For better interpretation and to distinguish between the upper and the lower halves of the scale, subjective social status was categorised into quartiles, with the highest (step 7-10), the second highest (step 6), the second lowest (step 5) and the lowest (step 1-4). Difficulty in paying bills reflects the financial ability to pay bills at the end of the month during the last 12 months, and has three categories; most of the time, from time to time and almost never/never.

\section{Demographic variables}

Demographic factors included gender, age, urbanisation and marital status. Age was used as a continuous variable. Urbanisation has three categories (rural area or village, small or middle sized town and large town). Marital status was dichotomised to indicate; married/living with a partner, versus single/divorced/separated/widowed.

\section{Statistical analyses}

\section{Latent class analysis}

To define which health-related behaviours naturally cluster together, latent class analysis was conducted using the five dichotomous variables by Mplus version 7.1. Latent class analysis has the most compelling methodological advantage in that it is based on probability modelling, which allows respondents to be assigned to the cluster to which they have the highest probability of belonging with taking into account that there is uncertainty about an object's class membership [36].

A class-specific response probability, which is estimated in latent class analysis, indicates how likely it is that a participant belonging to a particular cluster (e.g. risky cluster) has a certain behaviour (e.g. smoking). In this study, we regarded a probability of 0.50 or lower as a low probability, a probability between 0.50 and 0.75 as moderate, and a probabilities of 0.75 or higher as high for interpretation [18].

\section{Goodness-of-fit indexes}

Latent class analysis does not automatically determine the number of clusters by one single measure. Hence, the goodness-of-fit indexes of the estimated models are used to select the most suitable model depending on the purpose with the following measures. The likelihood ratio-goodnessof-fit chi-squared statistic $\left(L^{2}\right)$ indicates that the unexplained part of the observed relationships between the variables in the model. Hence, the smaller value indicates a model, which describes the better observed relationship and better fits the data. The $p$-value of $L^{2}$ is assessed based on the null hypothesis that the model is the true population model. The model fits data when $p$-value is more than 0.05 ideally [37].

There are some information criterions provided by latent class analysis, which weight model fit and parsimony. The smaller value indicates the better models [38]. The Bayesian Information Criterion (BIC) shows the value adjusting for the log likelihood value $(L L)$ of the number of parameters (Npar) in the model. The adjusted BIC, which additionally adjusting for a sample size, correctly identifies the number of classes more consistently across all models and all 
sample sizes for categorical latent class analysis models in addition to that the BIC is superior to all other information criterions for all modelling settings [39]. In this study, as we conducted an exploratory latent class analysis in order to determine the best number of the clusters on the data, there were no restrictions to form the clusters. Therefore, we used BIC and adjusted BIC to determine the number of the clusters.

\section{Assessment of association}

To examine the relationships between socioeconomic indicators and clusters of health-related behaviours identified by latent class analysis, multinomial logistic regression model was used by Stata 12. The model included socioeconomic indicators (education, subjective social status and difficulty in paying bills) and demographic factors (age, gender, urbanisation and marital status), and the healthy cluster was used as a reference. Survey command and survey weights (the population sized and post-stratification weights) were used to account for the survey complexity and variations between countries and to produce population-level estimates.

\section{Results}

A total of 23,842 participants from 27 European countries were included in this study after excluding those with missing data. As there were five health-related behaviours, models with one to four latent classes were estimated using latent class analysis. Model-fit indices are presented in Table 1. The one-cluster model was a baseline model, which assumes that the observed health-related behaviours are mutually independent and there is no association available to explain the relationship among the healthrelated behaviours. The model fit measures indicated that the three cluster model presented the most adequate solution for the data. Although the $p$-value corresponding to $L^{2}$ should formally be greater than 0.05 to conclude that a model fits the data, in this case it was considered acceptable given the very large sample size. Furthermore, the 3cluster model had the lowest values BIC and adjusted BIC, which indicated that it was the preferred model according to that criterion.
Latent class analysis found three classes based on five health-related behaviours. The weighted percentages were $26.50 \%(n=6312)$ for class $1,15.84 \%(n=3411)$ and $57.65 \%(n=14,119)$. Figure 1 exhibits the cluster-specific estimated probabilities of health-related behaviours for the three-cluster model from latent class analysis. Class 1 had a moderate possibility of dental check-ups and lower possibilities for other four behaviours. Class 2 had a high probability of smoking and lower possibilities for other four variables. In addition, class 3 had a higher probability of fresh fruit consumption, and had a moderate probability of physical activity. Therefore, class 1 was named as "moderate cluster", class 2 was named as "risky cluster" and class 3 was named as "healthy cluster".

Table 2 shows the distribution of demographic indicators by the three clusters. Healthy cluster was more common among females, married individuals and those living in rural area/village and those with higher socioeconomic positions.

There were clear socioeconomic gradients in clusters of health-related behaviours (Table 3). Individuals with the lowest socioeconomic positions were more likely to have risky or moderate cluster than healthy cluster compared with those with the highest socioeconomic position. Among the three socioeconomic indicators, difficulty in paying bills showed the most significant and consistent gradients in cluster of health-related behaviours with those unable to paying bills from time to time and most of the time having relative risk ratios of 1.58 ( $95 \%$ CI: 1.37 , $1.83)$ and 2.44 (95\% CI: $2.00,2.99)$ for risky cluster compared to those without difficulty in paying bills. Females and older people were less likely to have moderate cluster and risky cluster than healthy cluster compared to males and younger people.

\section{Discussion}

This study firstly explored the clusters of five health-related behaviours, namely smoking, excessive alcohol consumption, fresh fruit consumption, physical activity and dental check-ups in the population in 27 European countries. Latent class analysis identified three clusters (healthy,

Table 1 Model-fit indices for latent class analysis for health-related behaviours ( $N=23,842$; Eurobarometer 72.3, 2009, EU)

\begin{tabular}{llllllll}
\hline & Npar $^{\mathrm{a}}$ & $L^{2 \mathrm{~b}}$ & $d f^{\mathrm{c}}$ & $L^{2} p$-value & $L^{\mathrm{d}}$ & BIC $^{\mathrm{e}}$ & BIC*9 $^{*}$ \\
\hline 1-cluster model & 5 & 1860.948 & 26 & $<0.001$ & $-73,682.140$ & $147,414.676$ & $147,398.786$ \\
2-cluster model & 11 & 264.915 & 20 & $<0.001$ & $-72,884.123$ & $145,879.117$ & $145,844.160$ \\
3-cluster model & 17 & 50.953 & 14 & $<0.001$ & $-72,777.142$ & $145,725.631$ & $145,671.606$ \\
4-cluster model & 23 & 19.064 & 8 & 0.0145 & $-72,761.198$ & $145,754.217$ & $145,681.124$
\end{tabular}

${ }^{\mathrm{a}}$ Number of parameters in the model

${ }^{\mathrm{b}}$ Model Fit Likelihood ratio chi-squared statistic

'Degrees of freedom in the model

d $p$-value of $L^{2}$

eLog likelihood

fBayesian Information criterion, based on the log likelihood

${ }^{g}$ Bayesian Information criterion using sample size adjustment 


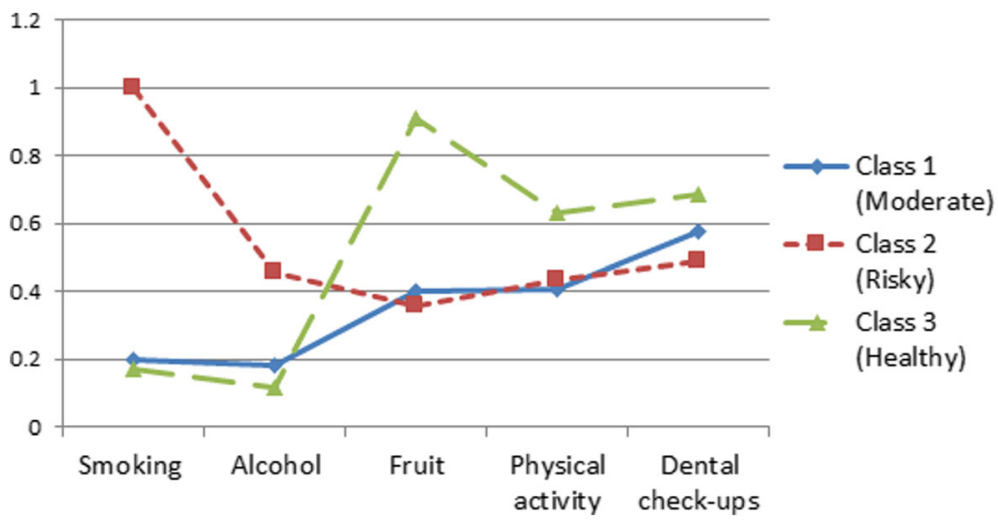

Fig. 1 Cluster-specific probabilities of health-related behaviours for the three-cluster model ( $N=23,842$; Eurobarometer $72.3,2009$, EU)

Table 2 Characteristics of the clusters ( $N=23,842$; Eurobarometer 72.3, 2009, EU)

\begin{tabular}{|c|c|c|c|c|c|c|c|c|c|c|}
\hline & \multicolumn{3}{|c|}{ Healthy } & \multicolumn{3}{|c|}{ Moderate } & \multicolumn{3}{|l|}{ Risky } & \multirow{3}{*}{$\begin{array}{l}P \\
\text { value }\end{array}$} \\
\hline & \multirow[t]{2}{*}{$\mathrm{n}$} & \multirow{2}{*}{\multicolumn{2}{|c|}{$\begin{array}{l}\% \quad(95 \% \mathrm{Cl}) \\
\text { Mean } \pm \mathrm{SE}\end{array}$}} & $\mathrm{n}$ & $\%$ & $(95 \% \mathrm{Cl})$ & $n$ & $\%$ & $(95 \% \mathrm{Cl})$ & \\
\hline & & & & & \multicolumn{2}{|c|}{ Mean \pm SE } & & \multicolumn{2}{|c|}{ Mean \pm SE } & \\
\hline \multicolumn{11}{|l|}{ Gender } \\
\hline Male & 5132 & 40.25 & $(38.96,41.56)$ & 3143 & 55.00 & $(53.09,56.89)$ & 2178 & 64.48 & $(61.97,66.92)$ & \multirow[t]{2}{*}{$<0.001$} \\
\hline Female & 8987 & 59.75 & $(58.44,61.04)$ & 3169 & 45.00 & $(43.11,46.91)$ & 1233 & 35.52 & $(33.08,38.03)$ & \\
\hline Age in years & \multicolumn{3}{|c|}{$50.40 \pm 0.23$} & \multirow[t]{2}{*}{6312} & \multicolumn{2}{|c|}{$46.30 \pm 0.35$} & 3411 & \multicolumn{2}{|c|}{$40.25 \pm 0.38$} & \\
\hline \multicolumn{10}{|l|}{ Urbanisation } & \\
\hline Rural area/village & 5162 & 35.19 & $(33.96,36.44)$ & 2286 & 35.17 & $(33.36,37.03)$ & 1176 & 32.68 & $(30.20,35.27)$ & \multirow[t]{3}{*}{$<0.001$} \\
\hline Small/middle sized town & 4991 & 40.49 & $(39.21,41.79)$ & 2203 & 39.65 & $(37.75,41.58)$ & 1166 & 38.37 & $(35.80,41.01)$ & \\
\hline Large town & 3966 & 24.31 & $(23.25,25.40)$ & 1823 & 25.17 & $(23.59,26.83)$ & 1069 & 28.94 & $(26.65,31.35)$ & \\
\hline \multicolumn{11}{|c|}{ Marital status } \\
\hline Married/with a partner & 9534 & 68.00 & $(66.80,69.18)$ & 4052 & 65.04 & $(63.20,66.84)$ & 2022 & 58.88 & $(56.23,61.48)$ & \multirow[t]{2}{*}{$<0.001$} \\
\hline Single & 4585 & 32.00 & $(30.82,33.20)$ & 2260 & 34.86 & $(33.16,36.80)$ & 1389 & 41.12 & $(38.52,43.77)$ & \\
\hline \multicolumn{11}{|l|}{ Education } \\
\hline 20 years or older & 4761 & 30.45 & $(29.28,31.65)$ & 1972 & 30.48 & $(28.71,32.30)$ & 841 & 24.26 & $(22.07,26.58)$ & \multirow[t]{3}{*}{$<0.001$} \\
\hline 16-19 years & 6257 & 43.86 & $(42.58,45.16)$ & 2950 & 46.31 & $(44.39,48.24)$ & 1896 & 56.28 & $(53.64,58.88)$ & \\
\hline 15 years or less & 3101 & 25.68 & $(24.55,26.85)$ & 1390 & 23.22 & $(21.65,24.86)$ & 674 & 19.47 & $(17.52,21.58)$ & \\
\hline \multicolumn{11}{|l|}{ Subjective social status } \\
\hline Highest & 4347 & 28.85 & $(27.69,30.03)$ & 1741 & 25.61 & $(24.01,27.29)$ & 801 & 23.94 & $(21.77,26.25)$ & \multirow[t]{4}{*}{$<0.001$} \\
\hline Second highest & 3007 & 24.76 & $(23.63,25.92)$ & 1421 & 25.55 & $(23.86,27.31)$ & 663 & 20.44 & $(18.39,22.66)$ & \\
\hline Second lowest & 4200 & 30.49 & $(29.30,31.70)$ & 1707 & 28.76 & $(27.01,30.57)$ & 1027 & 29.95 & $(27.51,32.51)$ & \\
\hline Lowest & 2565 & 15.91 & $(15.01,16.85)$ & 1443 & 20.09 & $(18.61,21.64)$ & 920 & 25.67 & $(23.44,28.03)$ & \\
\hline \multicolumn{11}{|l|}{ Difficulty in paying bills } \\
\hline Almost never/never & 9669 & 70.66 & $(69.48,71.82)$ & 3948 & 64.66 & $(62.81,66.47)$ & 1675 & 52.3 & $(49.64,54.94)$ & \multirow[t]{3}{*}{$<0.001$} \\
\hline From time to time & 3419 & 23.55 & $(22.47,24.66)$ & 1759 & 27.08 & $(25.42,28.82)$ & 1173 & 34.15 & $(31.70,36.69)$ & \\
\hline Most of the time & 1031 & 5.79 & $(5.25,6.39)$ & 605 & 8.25 & $(7.29,9.34)$ & 563 & 13.55 & $(11.94,15.34)$ & \\
\hline
\end{tabular}


Table 3 Relative risk ratios for the relationships between socioeconomic indicators and clusters from multinomial logistic regression analyses ( $N=23,842$; Eurobarometer 72.3, 2009, EU)

$\begin{array}{lll}\frac{\text { Moderate (vs Healthy) }}{\operatorname{RRR}} \quad(95 \% \mathrm{Cl}) & & \text { Risky (vs Healthy) } \\ \operatorname{RRR}(95 \% \mathrm{Cl})\end{array}$

\begin{tabular}{|c|c|c|c|c|}
\hline \multicolumn{5}{|l|}{ Gender } \\
\hline Male & 1 & & 1 & \\
\hline Female & 0.53 & $(0.48,0.59)$ & 0.34 & $(0.30,0.39)$ \\
\hline Age in years & 0.99 & $(0.98,0.99)$ & 0.97 & $(0.96,0.97)$ \\
\hline \multicolumn{5}{|l|}{ Urbanisation } \\
\hline Rural area/village & 1 & & 1 & \\
\hline Small/middle sized town & 0.99 & $(0.88,1.10)$ & 1.03 & $(0.89,1.20)$ \\
\hline Large town & 0.99 & $(0.88,1.12)$ & 1.17 & $(0.99,1.37)$ \\
\hline \multicolumn{5}{|l|}{ Marital status } \\
\hline Married/with a partner & 1 & & 1 & \\
\hline Single & 1.16 & $(1.05,1.29)$ & 1.37 & $(1.20,1.56)$ \\
\hline \multicolumn{5}{|l|}{ Education } \\
\hline 20 years or older & 1 & & 1 & \\
\hline $16-19$ years & 1.10 & $(0.98,1.23)$ & 1.74 & $(1.49,2.03)$ \\
\hline 15 years or less & 1.15 & $(0.99,1.33)$ & 1.73 & $(1.40,2.13)$ \\
\hline \multicolumn{5}{|l|}{ Subjective social status } \\
\hline Highest & 1 & & 1 & \\
\hline Second highest & 1.18 & $(1.04,1.35)$ & 0.99 & $(0.82,1.19)$ \\
\hline Second lowest & 1.08 & $(0.95,1.23)$ & 1.15 & $(0.96,1.38)$ \\
\hline Lowest & 1.37 & $(1.18,1.59)$ & 1.57 & $(1.29,1.91)$ \\
\hline \multicolumn{5}{|l|}{ Difficulty in paying bills } \\
\hline Almost never/never & 1 & & 1 & \\
\hline From time to time & 1.14 & $(1.02,1.28)$ & 1.58 & $(1.37,1.83)$ \\
\hline Most of the time & 1.39 & $(1.16,1.68)$ & 2.44 & $(2.00,2.99)$ \\
\hline
\end{tabular}

The model included age, gender, marital status, urbanisation, education, subjective social status, and difficulty in paying bills

moderate and risky clusters) in this population. Secondly, the study showed socioeconomic inequalities in the clusters of health-related behaviours, with those at the bottom of social hierarchy more likely to have risky and moderate clusters than those with the highest socioeconomic positions across all socioeconomic indicators.

This study used a latent class modelling to explore the clusters of health-related behaviours by the probabilitybased model rather than counting number of health risk behaviours in 27 European countries with nationally representative samples. Although it is also important to observe the number of health risk behaviours to reduce disease risks, the use of this clustering technique provides proper insights of the determinants of behaviours due to complexity of the relationships among health-related behaviours [16]. This study could potentially help to identify population at disease risk, which would possibly reduce the cumulative negative effects of health risk behaviours while improving efficiency [15].

Although a few other papers used latent class analysis, none of them examined socioeconomic inequality in the clusters $[17,18]$. The current study uniquely examined five health-related behaviours including dental check-ups which reflect preventive use of services. This provides insight of the socioeconomic characteristics of clustering health-related behaviours from a different view in this specific population. The study demonstrated socioeconomic inequalities in this cluster of behaviours in a large sample of European.

One of the strengths of this study is the use of both objective and subjective socioeconomic indicators to examine socioeconomic inequalities. Education and difficulty in paying bills reflect educational/material inequality due to the nature of the indicators while subjective social status reflects subjective/psychosocial inequality because this indicator was measured by the comparison among the society where the individuals belong to. Education is associated with future jobs and income, and with improvement of healthy literacy and knowledge related to enhancing healthrelated behaviours [22]. In other words, highly educated individuals gave greater chances/opportunities to obtain and follow information pertaining to health-related behaviours than their least educated counterparts [20]. Although the allocation of people still studying might not reflect their socioeconomic position properly, it is assumed that the chances/opportunities for obtaining the information among people with the same age would be equally provided in the same educational categories. In addition, material ability is also correlated with participation in various health promoting behaviours. For example, the cumulative effect of economic hardship leads to poorer physical, psychological and cognitive functioning [40]. Thus, material deprivation affects health and health-related behaviours directly and indirectly. Subjective social status which largely reflect perception of status within own community is appropriate for cross-countries comparisons and is an important marker of relative deprivation which is linked to health and related behaviours through psychological pathways [41].

Difficulty in paying bills showed the highest odds ratios and the most consistent gradients in any models although education and subjective social status also showed significant gradients in the clusters of health-related behaviours. The results indicate that financial abilities had the strongest influence on having multiple health-related behaviours. Policies and strategies which support economically disadvantaged people could be more effective than behaviour changing intervention that tackles individual behaviours. Having said this, it is also worth noting that even better educated or employed individuals could perceive lower social status, and this may not be improved only with strategies of financial support. This observation suggests that developing and implementing specific interventions for socioeconomically 
disadvantaged individuals might not be sufficient to reduce inequalities in multiple health-related behaviours. On the other hand, a whole community approach that aims at improving the living environment for everyone might be more effective on producing sustainable changes in the behaviours of the whole society [42]. For example, in the past couple of decades banning smoking in many western countries appeared to be effective in reducing morbidity and mortality [43]. Similarly, introduction of safety measures for cyclists, availability of affordable healthy food, sugar and alcohol taxation could have a greater impact on the whole population than specific interventions targeting smaller groups of individuals [44, 45].

In addition, females were less likely, and singles were more likely to have risky cluster. Previous clustering studies using co-occurrence of number of health risk behaviours reported that more health risk behaviours were related to male gender and singles $[11,12]$. This indicated that males and singles tended to have not only more number of risk behaviours but also a combination of health risk behaviours. The method used here helped identifying homogeneous clusters of behaviours and their socio-demographic determinants that could be generalised to European population.

This study has the advantage of using latent class analysis to identify healthy, moderate and risky clusters of five health-related behaviours including the four commonly used health-related behaviours and dental check-ups as an indicator for use of preventive services. The study also used three indicators of socioeconomic position reflecting different pathways to health-related behaviours in a large sample of the European countries.

There are a few limitations in this study. Firstly, this is a cross-sectional study, thus causality cannot be inferred. Secondly, some specific country's characteristics, such as geographical, cultural, ethnic and macroeconomic factors, could have influenced the findings. However, the use of survey weights accounts for this limitation.

\section{Conclusion}

There were clear socioeconomic gradients in these clusters of health-related behaviours with all socioeconomic indicators. The findings highlight the importance of adopting interventions that address multiple health risk behaviours and policies that tackle the social determinants of healthrelated behaviours.

\section{Abbereviations}

BIC: Bayesian Information Criterion; $L L$ : The log likelihood value; $L^{2}$ : The likelihood ratio-goodness-of-fit chi-squared statistic; Npar: The number of parameters

\section{Acknowledgements}

None

Funding

Open access for this article was funded by King's College London.

\section{Availability of data and materials}

The dataset generated and/or analysed during the current study and the questionnaire are available in the Eurobarometer 72.3: Public Health Attitudes, Behaviour, and Prevention, October 2009 (ICPSR32441), http:// www.icpsr.umich.edu/icpsrweb/ICPSR/studies/32441.

\section{Authors' contributions}

All authors jointly conceived of the study, read and approved the final version of the manuscript. SK designed the study, analysed the data and drafted the manuscript. EB commented on, and contributed to the study design and the manuscript. WS advised on the study design and data analysis, commented on and contributed to the manuscript.

\section{Competing interests}

The authors declare that they have no competing interests.

\section{Consent for publication}

Not applicable.

Ethics approval and consent to participate

Ethics approval is not required for this secondary analysis study.

\section{Publisher's Note}

Springer Nature remains neutral with regard to jurisdictional claims in published maps and institutional affiliations.

Received: 8 December 2016 Accepted: 15 May 2017

Published online: 23 May 2017

\section{References}

1. Danaei G, Vander Hoorn S, Lopez AD, Murray CJ, Ezzati M, group CRAC. Causes of cancer in the world: comparative risk assessment of nine behavioural and environmental risk factors. Lancet. 2005;366(9499):1784-93.

2. Hu FB, Manson JE, Stampfer MJ, Colditz G, Liu S, Solomon CG, et al. Diet, lifestyle, and the risk of type 2 diabetes mellitus in women. N Engl J Med. 2001;345(11):790-7.

3. Chow CK, Jolly S, Rao-Melacini P, Fox KA, Anand SS, Yusuf S. Association of diet, exercise, and smoking modification with risk of early cardiovascular events after acute coronary syndromes. Circulation. 2010;121(6):750-8.

4. Hanioka T, Ojima M, Tanaka K, Matsuo K, Sato F, Tanaka H. Causal assessment of smoking and tooth loss: a systematic review of observational studies. BMC Public Health. 2011;11(1):221.

5. Goldstein BY, Chang S-C, Hashibe M, La Vecchia C, Zhang Z-F. Alcohol consumption and cancer of the oral cavity and pharynx from 1988 to 2009: an update. Eur J Cancer Prev. 2010;19(6):431.

6. Moynihan P. The role of diet in the prevention of dental diseases, Comprehensive Preventive Dentistry. Hoboken: Wiley-Blackwell: 2012.

7. Tada A, Watanabe T, Yokoe H, Hanada N, Tanzawa H. Relationship between the number of remaining teeth and physical activity in community-dwelling elderly. Arch Gerontol Geriat. 2003;37(2):109-17.

8. Montero J, Albaladejo A, Zalba J, Castaño A, Mirón J, Del Castillo R. Influence of the usual motivation for dental attendance on dental status and oral health-related quality of life. Medicina Oral, Patologia Oral Y Cirugia Bucal. 2013;19(3):e225-31.

9. Sanders AE, Spencer AJ, Slade GD. Evaluating the role of dental behaviour in oral health inequalities. Community Dent Oral Epidemiol. 2006;34(1):71-9.

10. Pampel FC, Krueger PM, Denney JT. Socioeconomic disparities in health behaviors. Annu Rev Sociol. 2010:36:349.

11. Fine $L$, Philogene GS, Gramling R, Coups EJ, Sinha S. Prevalence of multiple chronic disease risk factors: 2001 National Health Interview Survey. Am J Prev Med. 2004;27(2):18-24.

12. Pronk NP, Anderson LH, Crain AL, Martinson BC, O'Connor PJ, Sherwood NE, et al. Meeting recommendations for multiple healthy lifestyle factors: prevalence, clustering, and predictors among adolescent, adult, and senior health plan members. Am J Prev Med. 2004:27(2):25-33.

13. Blane D, Smith GD, Bartley M. Social selection: what does it contribute to social class differences in health? Sociol Health IIIn. 1993:15(1):1-15.

14. McAloney K, Graham H, Law C, Platt L. A scoping review of statistical approaches to the analysis of multiple health-related behaviours. Prev Med. 2013;56(6):365-71. 
15. Yusuf S, Hawken S, Ônpuu S, Dans T, Avezum A, Lanas F, et al. Effect of potentially modifiable risk factors associated with myocardial infarction in 52 countries (the INTERHEART study): case-control study. Lancet. 2004; 364(9438):937-52.

16. Horn B, Huang W. Comparison of segmentation approaches. Decision Analyst: Arlington, TX; 2009

17. Funderburk JS, Maisto SA, Sugarman DE, Wade M. The covariation of multiple risk factors in primary care: a latent class analysis. J Behav Med. 2008;31(6):525-35.

18. De Vries H, van't Riet J, Spigt M, Metsemakers J, van den Akker M, Vermunt $\mathrm{JK}$, et al. Clusters of lifestyle behaviors: results from the Dutch SMILE study. Prev Med. 2008;46(3):203-8.

19. Marmot M, Wilkinson RG. Psychosocial and material pathways in the relation between income and health: a response to Lynch et al. Br Med J. 2001;322(7296):1233-6

20. Bartley M. Health inequality: an introduction to theories, concepts and methods. Cambridge: Polity Press; 2004

21. Aue K, Roosen J, Jensen HH. Poverty dynamics in Germany: evidence on the relationship between persistent poverty and health behavior. Soc Sci Med. 2016;153:62-70.

22. Galobardes B, Shaw M, Lawlor DA, Lynch JW, Smith GD. Indicators of socioeconomic position (part 1). J Epidemiol Community Health. 2006;60(1):7-12.

23. Singh-Manoux A, Marmot MG, Adler NE. Does subjective social status predict health and change in health status better than objective status? Psychosom Med. 2005;67(6):855-61.

24. Marmot MG. Understanding social inequalities in health. Perspect Biol Med. 2003;46(3):S9-S23.

25. Jensen RT, Richter $K$. The health implications of social security failure: evidence from the Russian pension crisis. J Public Econ. 2004;88(1):209-36.

26. Wilkinson RG. Socioeconomic determinants of health. Health inequalities: relative or absolute material standards? Br Med J. 1997;314(7080):591.

27. Blázquez $\mathrm{M}$, Cottini E, Herrarte A. The socioeconomic gradient in health: how important is material deprivation? J Econ Inequal. 2014;12(2):239-64.

28. Galobardes B, Lynch J, Smith GD. Measuring socioeconomic position in health research. Br Med Bull. 2007:81(1):21-37.

29. Martikainen $\mathrm{P}$, Valkonen $\mathrm{T}$. Bias related to the exclusion of the economically inactive in studies on social class differences in mortality. Int J Epidemiol. 1999;28(5):899-904.

30. ICPSR Codebook. [http://www.icpsr.umich.edu/icpsrweb/ICPSR/studies/32441].

31. Gmel G, Kuntsche E, Rehm J. Risky single-occasion drinking: bingeing is not bingeing. Addiction. 2011;106(6):1037-45.

32. Deutsche Hauptstelle für Suchtfragen e.V. Binge drinking and Europe. Hamm: DHS; 2008

33. EU Working Group. EU Physical Activity Guidelines - Recommended Policy Actions in Support of Health-Enhancing Physical Activity. Brussels; 2008.

34. Secondary education across Europe: Curricula and school examination systems. [http://www.leeds.ac.uk/educol/documents/00001195.htm].

35. Liberatos $P$, Link BG, Kelsey JL. The measurement of social class in epidemiology. Epidemiol Rev. 1988;10(1):87-121.

36. Hagenaars JA, McCutcheon AL. Applied latent class analysis. Cambriedge: Cambridge University Press; 2002.

37. McCutcheon AL. Latent class analysis. Lincoln: Sage; 1987.

38. Vermunt JK, Magidson J. Latent class analysis. In: Lewis-Beck MS, Bryman A, and Liao TF, editors. The Sage Encyclopedia of Social Sciences Research Methods. Thousand Oaks: Sage Publications; 2004. p. 549-53.

39. Nylund KL, Asparouhov T, Muthén BO. Deciding on the number of classes in latent class analysis and growth mixture modeling: a Monte Carlo simulation study. Struct Equ Model Multidiscip J. 2007;14(4):535-69.

40. Lynch JW, Kaplan GA, Shema SJ. Cumulative impact of sustained economic hardship on physical, cognitive, psychological, and social functioning. New Engl Med. 1997;337(26):1889-95.

41. Eibner C, Evans WN. Relative deprivation, poor health habits, and mortality. J Hum Resour. 2005:40(3):591-620.

42. Rose G. Sick individuals and sick populations. Int J Epidemiol. 2001;30(3):427-32

43. Been JV, Nurmatov UB, Cox B, Nawrot TS, van Schayck CP, Sheikh A. Effect of smoke-free legislation on perinatal and child health: a systematic review and meta-analysis. Lancet. 2014:383(9928):1549-60.

44. Stewart G, Anokye NK, Pokhrel S. What interventions increase commute cycling? A systematic review. BMJ Open. 2015;5(8):e007945.

45. Black AP, Brimblecombe J, Eyles H, Morris P, Vally H, O Dea K. Food subsidy programs and the health and nutritional status of disadvantaged families in high income countries: a systematic review. BMC Public Health. 2012;12:1099.

\section{Submit your next manuscript to BioMed Central and we will help you at every step:}

- We accept pre-submission inquiries

- Our selector tool helps you to find the most relevant journal

- We provide round the clock customer support

- Convenient online submission

- Thorough peer review

- Inclusion in PubMed and all major indexing services

- Maximum visibility for your research

Submit your manuscript at www.biomedcentral.com/submit
Biomed Central 